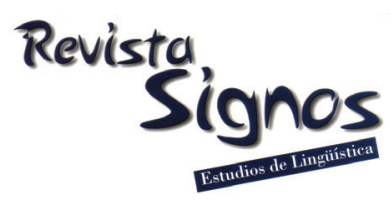

\title{
De labradores a pistoleros: El Movimiento de los Trabajadores Rurales sin Tierra en la revista Veja
}

\author{
From peasants to gunmen: The Brazilian Landless Movement \\ in Veja magazine
}

\section{Cláudia Mendes Giesel}

Universidad Veiga de Almeida

BRASIL

claudia4justice@hotmail.com
Fernando Ramallo

UNIVERSIDAD DE VIGO

EsPAÑA

framallo@uvigo.es

Recibido: 5-V-2011 / Aceptado: 4-I-2012

\section{Resumen}

La representación elaborada por el semanario brasileño Veja con respecto a los movimientos sociales que cuestionan el status quo brasileño revela la tendencia de ese medio a dar cuenta de los aconteceres a partir de construcciones semánticamente negativas. Esto es especialmente relevante en el tratamiento discriminatorio del Movimento dos Trabalhadores Rurais sem Terra (MST) lo que conlleva una interpretación poco favorable del mismo. El objetivo de este trabajo es ofrecer un análisis crítico de las estrategias discursivas de Veja a partir de las determinaciones y de las prácticas sociales de la revista en la producción y en la reproducción de la identidad del MST. Para ello, seleccionamos el universo de reportajes publicados en Veja entre los años 1984-2009 en los que el MST es el eje temático y los dividimos en 5 períodos políticos diferentes. La investigación muestra cómo los diferentes períodos políticos seleccionados han tenido consecuencias en la construcción de una imagen cada vez más negativa del MST.

Palabras Clave: MST, denominación, revista Veja, análisis crítico del discurso, mediación social. 


\begin{abstract}
The representation elaborated by the Veja Magazine about social movements that questions the Brazilian status quo shows a clear tendency of the magazine to broadcast facts from semantically negative constructions. This is particular relevant in the discriminatory treatment adopted by the magazine to refer to the Brazilian Landless Movement (MST), what consequently leads to an unfavorable interpretation of the movement. The goal of this article is to offer a critical analysis of the discursive strategies of Veja from the determinations and the social practices of the magazine in the production and the reproduction of the MST's identity. We have selected articles published in Veja from January 1984 to February 2009 in which the MST was the focus and divided them into 5 political periods. The findings show that the different selected political periods were significant in the construction of an increasingly negative image of the MST.
\end{abstract}

Key Words: Brazilian Landless Movement, naming, Veja magazine, critical discourse. analysis, social mediation.

\title{
INTRODUCCIÓN
}

En la fase histórica actual, los medios de comunicación operan en una lógica destinada no solo a proporcionar información sobre los aconteceres sino que principalmente constituyen aparatos ideológicos que acumulan un gran poder, si no formal, sí de facto. En todo caso, un componente muy habitual de la estrategia ideológica de los medios es predicar su imparcialidad como productores de información, lo cual supone un desafío a su propia esencia. Los medios 'median' estructural y cognitivamente, seleccionando aconteceres y estrategias comunicativas para cambiar o para mantener estructuras de poder (Martín Serrano, 1986). Por ello y para ello, son 'necesariamente' parciales.

Como en otras partes, en Brasil los medios de comunicación han jugado un papel importante en la (de)construcción de la opinión pública, mediante información que se filtra a partir de marcos ideológicos que muchas veces van en contra de los intereses necesarios para crear una ciudadanía más plural, justa y democrática. En este proceso de filtración y edición de la información para perpetuar ideologías, la lengua desempeña un papel muy significativo, no solo en la interacción expresiva sino especialmente como instrumento para controlar el mundo y el orden social (Fairclough, 1989).

Con estos presupuestos, el tratamiento informativo de los movimientos sociales constituye una temática relevante en la construcción mediática de la realidad social brasileña. En particular, el Movimento dos Trabalhadores Rurais Sem-Terra (desde ahora, 
MST), surgido en la década de 1980 en la Región Sur de Brasil, para presionar al gobierno hacia la reforma agraria, ha ido aumentando su presencia en los medios, no solo como objeto noticiable sino sobre todo como foco en la construcción de un determinado discurso ideológico. Esto ha tenido como consecuencia una presencia muy relevante del MST en los medios brasileños, lo que ha derivado en la elaboración, distribución y transformación de diversas representaciones desde diferentes perspectivas sociales, culturales, ideológicas y lingüísticas.

La revista Veja, considerada la de más audiencia de Brasil y sobre la que hemos elaborado el corpus de esta investigación, ha jugado un papel importante en la construcción de buena parte de esas representaciones sobre el MST. Muchos estudios han sido realizados sobre esta representación, pero son escasos los que hasta ahora se han detenido en analizarla mediante el contraste dialéctico derivado de observar los cambios ocurridos en diferentes períodos políticos del contexto brasileiro.

La neutralidad e imparcialidad de Veja, sin embargo, no parece estar en relación con el discurso de los innumerables artículos desde los que la revista se ha presentado al público. Dicho discurso presenta a la revista como un medio de comunicación fiable y de confianza. Esta estrategia contribuye a que la revista 'naturalice' su ideología neoliberal en favor de la propiedad privada, el libre mercado, la globalización, la agroindustria, y así sucesivamente. Además, también ayuda a la revista a desplazar semánticamente cualquier otra forma de entender la libertad y la democracia, lo que afecta en gran medida a la lucha del MST por la reforma agraria y por la justicia social en el país.

En el marco de los estudios del discurso, esta investigación asume como propia una perspectiva teórico-metodológica que entiende que el lenguaje no solo refleja la realidad social sino que además la construye. En Brasil, las formas de representación se han utilizado en gran medida por los medios de comunicación como una forma de perpetuar ideologías y mantener el status quo. En el caso del MST, las representaciones lingüísticas aparecen en formas diferentes destinadas a desacreditarlo. Por lo tanto, en este artículo, centramos nuestra atención en la denominación como una estrategia referencial para la construcción de una determinada representación social del MST en Veja. Por un lado, dicha estrategia sirve para proyectar sentidos ideológicamente calculados con respecto al referente, que orientan la percepción que sobre él elabora el destinatario; por otro lado, establecen relaciones de coherencia con respecto a la representación de otros actores sociales (Richardson, 2007). Es lo que van Dijk (2000: 61) denomina el principio del 'cuadrado ideológico', caracterizado por el recurso a una estrategia diseñada para "encontrar el énfasis en nuestras buenas cosas y en sus malas cosas, y, recíprocamente, la negación o atenuación de nuestras malas cosas y de sus buenas cosas".

Para nuestro análisis, abordamos las estrategias de denominación respecto del MST utilizadas por Veja desde 1984 a 2009, período que abarca 5 ciclos políticos posteriores 
a la dictadura militar y en los que se alternan en el poder posiciones ideológicas distintas. Por ello, la pregunta que pretende responder nuestra investigación es la siguiente: ¿qué cambios se han producido en la representación del MST elaborada por la revista Veja en los distintos períodos políticos posteriores al final de la dictadura en Brasil?

\section{Antecedentes}

En general, el análisis de la representación del MST por parte de los medios de comunicación brasileños muestra un juego ideológico con el lenguaje para presentarlo públicamente desde un marco fundamentalmente deslegitimador (véase, entre otros, Gonçalves, 2004; Moura dos Santos, 2007; Almeida Brasil, 2008; Passos, 2008).

En las últimas décadas, Veja ha sido objeto de estudio de numerosas investigaciones en el área del discurso, especialmente por su posicionamiento discursivo con respecto al MST. Pereira (2001), por ejemplo, analiza las estrategias que la revista utiliza para construir una imagen negativa del MST a partir del uso de un lenguaje totalitario que distorsiona y erosiona su papel en tanto que movimiento social emancipador "através de narrativas sem verossimilhança" (Pereira, 2001: 1).

Un estudio de investigación realizado por Tfouni y Romão (2004) también ha demostrado que Veja perpetúa un discurso ideológico conservador cuando aborda la temática relacionada con el MST. Los autores analizan la confrontación de dos formaciones discursivas utilizadas por los medios de comunicación brasileños para representar el MST. Para ello parten de las nociones de ideología, sujeto, memoria y significado para interpretar sus datos. Sus hallazgos sugieren que si de un lado las formaciones discursivas sirven para criminalizar el movimiento, de otro lado, contribuyen a la formación de un debate nacional sobre el MST, materializando un discurso de resistencia contra la clase dominante y en favor de la reforma agraria. En otras palabras, los autores sugieren que el discurso ideológico utilizado por los medios de comunicación genera un discurso de confrontación y resistencia que contribuye a romper el discurso dominante divulgado por los medios y a la construcción de un discurso en favor de la justicia social en el país.

Desde una perspectiva complementaria, Souza (2004) hace una análisis sociológico y lingüístico de Veja, el MST y el gobierno neoliberal de Fernando Henrique Cardoso. A firma que el discurso de la revista se rige por las prácticas neoliberales y es alimentado por las poderosas corporaciones que utilizan la revista para perpetuar sus puntos de vista de la sociedad. Veja, en consonancia con la mayoría de la prensa brasileña, toma partido con claridad y utiliza trazos lingüisticos y representaciones que contribuyen a la perpetuación de su discurso ideológico. Sin embargo, es importante tener en cuenta que en ese período la revista sitúa en un segundo plano el discurso sobre el MST, a la vez que se vuelve más suave o más duro en función de la situación política del país. En otras palabras, Veja se mueve al ritmo que rige la lógica de la clase hegemónica. 
Azevedo (2005) analiza desde la semántica cognitiva las denominaciones utilizadas por Veja para representar el MST. La autora menciona que la revista adopta un marco cognitivo basado en la agresión para describir al MST y a todas las acciones que están asociadas al movimiento. Las denominaciones adoptadas por Veja que se mencionan en el trabajo de Azevedo (2005) tienen profundas implicaciones ideológicas y políticas que están destinadas a minusvalorar el MST y a crear una imagen negativa del grupo. De esta manera se pretende inocular en la opinión pública una cierta aversión con respecto a las reivindicaciones del movimiento.

Viera y Giuliani (2007), a partir de la noción de detourment desarrollada por Guy Debord, analizan cómo el MST combate la criminalización de sus prácticas usando las armas propias de su enemigo, esto es, los medios brasileños. Por su parte, Azevedo (2008) examina, a partir de un estudio enfocado desde el análisis crítico del discurso y los estudios cognitivos, cómo las élites brasileñas se valen de los medios para establecer su discurso y deslegitimar el MST.

Además del léxico utilizado en las denominaciones, téngase en consideración que la revista recurre a otras estrategias discursivas para deslegitimar y desactivar todo aquello a lo que se opone el MST: topicalización, modalidad, ironía, hiperbolización, etc., algunas de ellas objeto de estudio de la investigación en la que se inserta este trabajo. Al hacer esto, Veja manifiesta una notoria parcialidad y trata de desvalorizar todo lo que no encaja en el sistema ideológico que la revista representa. Un ejemplo de este fenómeno lingüístico se puede encontrar en las obras de Benetti (2007), cuando se describe el uso de la ironía en Veja, en este caso, para describir las medidas adoptadas por el MST durante el gobierno de Luiz Inácio Lula da Silva. Según la autora, Veja adopta esta característica lingüística para desactivar algo o a alguien y para señalar su apoyo a las organizaciones empresariales, partidos políticos, etc., con fuertes lazos ideológicos y filosóficos contrarios al MST.

En Ferreira y Sombra (2008) encontramos un análisis de textos de Veja que representan el MST entre los años 2003-2004. Los autores apuntan que Veja, a partir de una concepción macroestructural sobre el nós y el eles, controla una argumentación ideológica para representar el MST.

También Guilherme (2008) analiza el discurso de la revista Veja hacia el MST y el gobierno de Lula da Silva. El autor sostiene que la revista predica la imparcialidad, pero hace todo lo contrario cuando presenta noticias manipulando los hechos para ajustarse a los intereses de los grupos que representa. En todo caso, Veja no siempre ha mantenido el mismo tono de discurso para describir el MST. El autor afirma que el discurso utilizado no ha sido uniforme, y menciona:

"enganam-se aqueles que pensam que o discurso da Revista Veja em relação ao MST sempre foi uniforme, muito pelo contrário, em tempos de FHC, a Revista saiu do silêncio em relação ao tema, para a satanização do Movimento" (Guilherme, 2008: 118). 


\subsection{Denominación, medios y MST}

Las formas de denominación constituyen una de las vías más inmediatas de construir representaciones del mundo, en particular para representar personas, lugares, naciones, minorías, etc. Por ello son objeto de estudio frecuente en el análisis crítico del discurso (van Leeuwen, 1996; Galasiński \& Skowronek, 2001; Wodak, 2001; Fairclough, 2003; Richardson, 2007; KhosraviNik, 2010; Rodríguez \& Williams, 2011). En el caso concreto de la representación del MST por el semanario Veja, Indursky (1999) describe y analiza las denominaciones por las que opta la revista para referirse a la ocupación de la tierra (o invasão, en palabras de Veja) realizada por el movimiento para presionar al gobierno en la planificación y ejecución de la reforma agraria. Según Indursky (1999), Veja insiste en el uso de 'invasores' con el fin de victimizar a los propietarios de la tierra y satanizar la imagen del MST. La autora cree que la revista posee una agenda ideológicamente construida cuando se define como neutra e imparcial en relación con el MST. Por otro lado, en Indursky (2002), se analiza la interconexión entre ética, política, asuntos legales y el MST en A Folha de São Paulo. En este trabajo, Indursky (2002) adopta la perspectiva de la tradición francesa del análisis del discurso y argumenta que $A$ Folha también utiliza las denominaciones 'invasores' y 'ocupantes' para deslegitimizar al Movimiento. Ella señala que estas elecciones están intrínsecamente vinculadas a la idea de propiedad privada y a la ilegalidad respectivamente, lo cual, en consecuencia, caracteriza al MST como una asociación malhechora desde el punto de vista ético.

Franco (2003), en un estudio realizado sobre prácticas discursivas, el MST y $A$ Folha de São Paulo, analiza la perpetuación del discurso de la clase dominante que se puede encontrar en Veja, y añade que el periódico controla y distorsiona la información presentada al público cuando se representa el movimiento recurriendo a denominaciones negativas impregnadas de prácticas ideológicas.

En un artículo que combina análisis del discurso y análisis de contenido, Ayoub (2007) coincide al señalar que $A$ Folha de São Paulo recurre a denominaciones negativas para representar el movimiento infravalorándolo. La autora argumenta que este proceso de desprestigio va en contra del principio del derecho a la información expresado en la Constitución brasileña y llama la atención sobre el discurso de la clase dominante perpetuado por la revista Veja.

\section{Fundamentos teóricos}

Este trabajo se enmarca en la tradición de estudios sobre el análisis de la representación social elaborado por los medios de comunicación. Siguiendo a Fairclough (1995), la representación constituye uno de los aspectos fundamentales que incorpora todo proceso mediacional, junto con la construcción de relaciones y la construcción de identidades. Los medios de comunicación son instituciones que elaboran sus representaciones de acuerdo con la lógica que emana de las relaciones de poder, de los intereses y objetivos de aquellos que los producen. 
El fundamento teórico de este trabajo se nutre de los aportes de dos perspectivas teórico analíticas muy contrastadas en el análisis de los medios de comunicación: el análisis crítico del discurso y la teoría social de la comunicación (Martín Serrano, 1986). Desde perspectivas teóricas diversas, el análisis crítico del discurso es considerado como un programa de investigación que concibe las sociedades modernas como espacios de interacción dominados por aquellos grupos que tienen un mayor control sobre los recursos simbólicos (véase Wodak, 2011) para una síntesis de los principales desafíos de la investigación actual en los distintos enfoques del análisis crítico del discurso). Su objetivo fundamental es evidenciar el rol del discurso en la producción y reproducción de relaciones estructurales de poder, desigualdad, dominación y control, casi nunca explícitas. En general, se adopta una relación dialéctica entre dos sistemas dinámicos: el discurso y la sociedad, de tal manera que lo social moldea el discurso y este, a su vez, contribuye a constituir y transformar lo social: situaciones, instituciones, estructuras, identidades, conocimiento y relaciones (Fairclough \& Wodak, 1997).

En tanto que perspectiva analítica, al análisis crítico del discurso ninguna práctica discursiva mediada le es ajena, por predominar en ellas el carácter ideológico, implícito o explícito. A través de su análisis se pueden visibilizar los esquemas interpretativos que sobre la sociedad, los grupos y las personas se vierten en la prácticas comunicativas socialmente institucionalizadas. Este énfasis en abordar el fenómeno ideológico y su proyección discursiva en la reproducción o en la transformación del status quo está en los fundamentos epistemológicos del análisis crítico del discurso y es uno de sus objetos de investigación más sistemáticos cuando se aborda el papel de las ideologías en la formación de las representaciones sociales (van Dijk, 1986, 1997, 2000; Fowler, 1991; Fairclough, 1995; Bell \& Garrett, 1998; Bernardo Paniagua, López García, Sancho Cremades \& Serra Alegre, 2007; Johnson \& Ensslin, 2007; Richardson, 2007; Johnson \& Milani, 2010; Montgomery, 2011). Los medios de comunicación se han convertido en instituciones fundamentales en la distribución de marcos ideológicos, al ser los principales instrumentos que el poder tiene a su disposición para legitimar la dominación. Desde el análisis crítico del discurso, el trabajo de van Dijk (1997) constituye la propuesta más completa para el abordaje de las ideologías, definidas como:

"...the basis of the social representations shared by members of a group. This means that ideologies allow people, as group members, to organize the multitude of social beliefs about what is the case, good or bad, right or wrong, for them, and to act accordingly" (van Dijk, 1997: 8).

Con respecto a la importancia de los medios como instituciones ideológicas de primer orden, ya Althusser (1970) mostró que la comunicación mediada institucionalmente constituye un poderoso aparato ideológico de dominación, incluida la represión simbólica. Desde luego, los medios de comunicación tradicionales han cambiado mucho desde esa época pero su función sigue intacta. Por ello, en una lógica semejante, Blommaert (2005: 163) considera que las ideas, no siendo en sí misma ideológicas, 
alcanzan ese estatus "as soon as it is picked up by power-regulating institutions such as the media and inserted into the ideological reproduction system they organize".

Para Fairclough $(1989,1995,2003)$ todo evento comunicativo puede ser visto como texto, práctica discursiva y práctica social. Al referirnos a eventos comunicativos elaborados por los medios de comunicación, observar el evento como práctica discursiva nos sitúa directamente en el análisis mediacional. Se trata de estudiar las representaciones (texto) teniendo presente los procesos de producción, distribución y consumo (práctica discursiva), en un marco ideológico determinado (práctica social) que, en nuestro análisis, aparece recuperado en los distintos contextos sociopolíticos en el que fueron producidos los textos que constituyen nuestro corpus.

Nuestra investigación ahonda en un estudio crítico del discurso desde un planteamiento teórico-metodológico que se nutre de la teoría social de la comunicación, en la medida en que se pretende estudiar cambios a partir de un diseño dialéctico, sistémico y crítico. La teoría social de la comunicación parte del hecho evidente de que la función esencial de los medios de comunicación es mediar entre los aconteceres y la opinión pública, recurriendo a la elaboración de productos comunicativos destinados a proporcionar esquemas interpretativos de la realidad en un momento histórico determinado (Martín Serrano, 1986). Estos esquemas interpretativos se orientan bien a la reproducción del statu quo, reforzando los mecanismos de dominación, bien a su transformación, elaborando representaciones sobre el acontecer que promueven el cambio social.

Así, lo que acontece es vigilado y seleccionado si es de interés para la comunidad; una vez seleccionado se representa y se comunica recurriendo a unas substancias expresivas con la finalidad de que sea (re)conocido por unas determinadas audiencias. De lo que se trata es de analizar lo que comunicativamente permanece y lo que se transforma con los cambios de régimen en Brasil con respecto al MST para indagar si se producen cambios en las representaciones y si es así cómo son esos cambios.

Como toda representación, también las representaciones sociales son esquemas cognitivos de substitución de la realidad. En este caso la construcción de tal representación deriva del intercambio comunicativo de información. Pues bien, la característica más resaltable de la comunicación producida en entornos sociales, esto es, aquella que se produce siguiendo normas institucionalmente legitimadas, es que el receptor no mantiene una relación directa con el objeto de referencia sino que la información que recibe del mismo fue seleccionada y elaborada por otro/s actor/es en un proceso de producción social de comunicación denominado 'mediación'. La mediación social se especializa en la función productiva y reproductiva del modelo de mundo más aceptado en un sistema social determinado. Se trata de buscar el ajuste y el consenso en las representaciones del mundo que elaboran los distintos miembros del grupo. Mediar, en este caso, equivale a integrar, proporcionando a la opinión pública interpretaciones del entorno y de lo que en él acontece (Martín Serrano, 1996). 
Desde los estudios del discurso, van Dijk aborda los procesos mediacionales a partir del triángulo conceptual: discurso, cognición y sociedad. No hay vínculos directos entre la sociedad y el discurso u otras prácticas sociales sino representaciones sociocognitivas que median entre la sociedad y el discurso (van Dijk, 2000).

\section{Metodología}

Para la elaboración de esta investigación creamos un corpus con la totalidad de los reportajes publicados en Veja sobre el MST entre enero de 1984 y febrero de 2009. En total han sido 53 artículos 1 . De ellos, seleccionamos una muestra de 34 teniendo en cuenta los siguientes criterios: a) al menos un artículo fue seleccionado de cada año; b) cuando había más de un artículo por año, por lo menos la mitad de los artículos fueron seleccionados y c) en los años con mayor número de artículos, al menos uno fue seleccionado por cada trimestre. En estos mismos años, dimos preferencia a los artículos más extensos y, cuando fue posible, seleccionamos artículo publicados en meses diferentes. Tal como se muestra en la Tabla 1, al menos fueron seleccionados la mitad de los artículos encontrados en cada período político.

Tabla 1. Distribución del corpus y de la muestra por períodos políticos.

\begin{tabular}{|l|c|c|}
\hline Períodos políticos & Reportajes & Reportajes analizados \\
\hline $1984-1994$ & 5 & 4 \\
\hline $1995-1998$ & 13 & 8 \\
\hline $1999-2002$ & 13 & 7 \\
\hline $2003-2006$ & 19 & 12 \\
\hline $2007-2009$ (febrero) & 3 & 3 \\
\hline TOTAL & $\mathbf{5 3}$ & $\mathbf{3 4}$ \\
\hline
\end{tabular}

Por sus características, el reportaje es el género periodístico idóneo para el análisis de representaciones sociales. El hecho de combinar diversidad funcional, temática, compositiva y estilística convierte a este tipo de textos en un objeto analítico de gran versatilidad (Fernández Parrat, 1998). Su elección nos ha permitido acceder a textos extensos, valorativos e interpretativos relacionados con el MST, lo cual permite un análisis crítico de mayor alcance con respecto a la ideología subyacente en la Veja.

Veja, fundada en 1968, se publica semanalmente y en la actualidad es la revista de mayor circulación en Brasil. Ocupa el cuarto lugar mundial entre las revistas de información, con casi 10 millones de lectores. Veja se centra en temas que abarcan desde asuntos personales de la vida cotidiana a la educación, salud, cultura o política. Con datos de julio de 2011, alrededor del 88\% de la tirada semanal (1.200.000 ejemplares) se distribuye entre subscriptores y el resto está disponible para la venta ${ }^{2}$.

Aproximadamente un $70 \%$ de lectores pertenece a las clases altas y medias de Brasil. Por ello, aunque la publicación ha sido acusada de servir a los ideales de la clase dominante, favoreciendo prácticas y políticas conservadoras y neoliberales, que 
asocian el país con la corrupción, con las injusticias y con todo tipo de violencia (Azevedo, 2005), los fundadores de Veja siempre habían descrito la revista como una fuente independiente destinada a presentar las noticias del modo en que estas suceden. En otras palabras, según la revista, su objetivo principal es describir los hechos tal como se presentan.

\section{Análisis y discusión}

Las denominaciones utilizadas por la revista para representar el MST en los períodos estudiados se presentan a partir de tres ejes discursivos: como 'grupo social', como 'actor político' y como 'violencia'. Cada uno de ellos liga al actor social objeto de nuestra investigación con sentidos diferentes. La categoría 'grupo social' incluye las opciones léxicas que vinculan al MST con formas de estratificación social. La categoría 'actor político' recoge las entradas que representan al MST como un grupo político que representa al pueblo brasileño en un momento histórico determinado. Por último, la categoría 'violencia' recoge todas las denominaciones que caracterizan y sitúan las acciones del MST en la dimensión semántica del peligro, del terror, etc. Es decir, todas aquellas acciones que supuestamente amenazan el status quo establecido. La Tabla 2 recoge cada denominación y su cuantificación en cada período político estudiado y para cada eje discursivo propuesto. 
Tabla 2. Relación de denominaciones en cada período político para cada eje discursivo.

\begin{tabular}{|c|c|c|c|c|c|}
\hline \multirow[b]{2}{*}{$\begin{array}{l}\text { Ejes } \\
\text { discursivos }\end{array}$} & \multicolumn{5}{|l|}{ Períodos políticos } \\
\hline & 1984-1994 & 1995-1998 & 1999-2002 & $2003-2006$ & $2007-2009$ \\
\hline $\begin{array}{l}\text { Grupo } \\
\text { social }\end{array}$ & $\begin{array}{l}\text {-familias (12) } \\
\text {-lavradores (11) } \\
\text {-travalhadores } \\
\text { rurais (1) } \\
\text {-posseiros (7) } \\
\text {-deserdados (1) } \\
\text {-agricultores (2) } \\
\text {-sem-terra (11) } \\
\text {-gente brava (1) } \\
\text {-miseravéis (1) }\end{array}$ & $\begin{array}{l}\text { sem-terra (22) } \\
\text {-gente brava (1) } \\
\text {-gente honesta (1) } \\
\text {-pobre (1) } \\
\text {-assentados (15) } \\
\text {-sem nada (1) } \\
\text {-analfabetos (2) } \\
\text {-agricultores arruinados } \\
\text { (1) } \\
\text {-comerciários sem eira } \\
\text { nem beira (1) } \\
\text {-gente que foi bóia fria (1) } \\
\text {-famílias (4) } \\
\text {-pequenos agricultores (1) } \\
\text {-lúmpen (1) } \\
\text {-massa de pés descalços } \\
\text { (1) } \\
\text {-famintos (1) } \\
\text {-trabalhadores rurais (2) } \\
\text {-massa de pés descalços } \\
\text { (1) }\end{array}$ & $\begin{array}{l}\text {-legião de pobre (1) } \\
\text {-assentados (2) }\end{array}$ & $\begin{array}{l}\text {-excluídos do } \\
\text { capitalismo (1) } \\
\text {-miseravéis (2) } \\
\text { - bravos comba- } \\
\text { tentes do campo } \\
\text { (1) } \\
\text { - lavradores (3) } \\
\text {-famílias acampa- } \\
\text { das (1) } \\
\text {-biscateiros (3) } \\
\text {-desempregados } \\
\text { (1) } \\
\text {-motoristas (1) } \\
\text {-pequenos vende- } \\
\text { dores (1) } \\
\text {-pessoas que } \\
\text { desenvolvem ativi- } \\
\text { dades econômicas } \\
\text { marginais (1) }\end{array}$ & $\begin{array}{l}\text {-assentados (4) } \\
\text {-desvalidos (1) }\end{array}$ \\
\hline Violencia & \begin{tabular}{|l}
-invasores (3) \\
-posseiros armados \\
e desarmados (1) \\
-assassinos (1) \\
-manifestantes (1)
\end{tabular} & $\begin{array}{l}\text {-agitador (1) } \\
\text {-invasores (1) } \\
\text { - Adeptos das táticas } \\
\text { maoístas (1) } \\
\text {-simpatizantes do sandi- } \\
\text { nismo Nicaraguense (1) } \\
\text {-defensores de uma pátria } \\
\text { operária e socialista (1) } \\
\text {-organização a favor da } \\
\text { luta armada (1) }\end{array}$ & $\begin{array}{l}\text {-radicais (1) } \\
\text {-sem liminte (1) } \\
\text {-movimento políti- } \\
\text { co que manipula as } \\
\text { massas (1) } \\
\text {-maoístas (1) } \\
\text {-guevaristas (1) } \\
\text {-marxistas (1) } \\
\text {-fidelistas (1) } \\
\text {-bandidos (1) } \\
\text {-proxeneta da re- } \\
\text { forma agrária (1) } \\
\text {-sem causa (1) } \\
\text {-baderneiros (1) } \\
\text {-deserdados (1) } \\
\text {-sem chance (1) } \\
\text {-novos agricultores } \\
\text { da bandeira ver- } \\
\text { melha (1) }\end{array}$ & $\begin{array}{l}\text {-socialistas (1) } \\
\text {-comunistas (1) } \\
\text {-revolucionários } \\
(1) \\
\text {-aproveitadores (1) } \\
\text {-facínoras (1) } \\
\text {-organização crimi- } \\
\text { nosa (1) }\end{array}$ & $\begin{array}{l}\text {-maoistas (1) } \\
\text {-banditos (2) } \\
\text {-criminosos (1) } \\
\text {-malfeitores (1) } \\
\text {-leninistas (1) } \\
\text {-organização } \\
\text { clandestina } \\
\text {-gangues (1) } \\
\text {-invasores (2) } \\
\text { - bando de pisto- } \\
\text { leiros (1) } \\
\text {-aproveitadores } \\
\text { (1) }\end{array}$ \\
\hline $\begin{array}{l}\text { Actor } \\
\text { político }\end{array}$ & -militantes (5) & $\begin{array}{l}\text {-Lideres (3) } \\
\text {-MST (7) } \\
\text {-organização vitoriosa (1) } \\
\text {-organização próspera (1) } \\
\text {-movimento de oposição } \\
\text { (1) } \\
\text {-força de oposição (1) }\end{array}$ & $\begin{array}{l}\text {-sem terra (12) } \\
\text {-MST (28) } \\
\text {-Manifestantes (2) } \\
\text {-correia de trans- } \\
\text { missão do PT (1) }\end{array}$ & $\begin{array}{l}\text {-MST (24) } \\
\text {-sem terra (2) } \\
\text {-camaradas (2) } \\
\text {-lideres iluminados } \\
\text { do lumpesinato (1) } \\
\text {-militantes (1) }\end{array}$ & $\begin{array}{l}\text {-MST (22) } \\
\text { - sem terra (9) } \\
\text {-militantes (1) } \\
\text {-integrantes (1) }\end{array}$ \\
\hline
\end{tabular}


Aunque no es objetivo de este trabajo realizar un análisis cuantitativo, una observación a la diversidad y a la cantidad de denominaciones nos muestra algunos datos de interés. En primer lugar, el período 1995-1998 es en el que se recurre a una mayor variedad en las estrategias de representación léxica del MST, aun no siendo la época en la que Veja ha dedicado más reportajes al movimiento (Tabla 1). Este periodo coincide con la fase en la que el gobierno federal, como reacción a la fuerte movilización del MST, pretendió convencer a la opinión pública de que estaba llevando a cabo una reforma agraria en el país. Pero esta opinión pública victimizó al MST como consecuencia de algunas confrontaciones con el movimiento, que redundó en una mayor visibilidad que en cualquiera de los otros períodos analizados, especialmente en la categoría 'grupo social'.

En segundo lugar, en el período 1999-2002 es en el que se contabilizan más denominaciones en la categoría 'violencia'. Además, esta categoría es la más relevante de las tres. Los últimos años de este período coinciden con una clara ventaja de Lula da Silva, candidato del PT, en las encuestas relacionadas con las elecciones presidenciales de 2002, teniendo al MST como uno de sus principales apoyos en el tejido asociativo. A diferencia del periodo anterior, ahora Veja demoniza al MST vinculándolo referencialmente con la violencia.

Por último, la categoría 'actor político' es la que menos diversidad léxica presenta en el conjunto de los períodos analizados. Sin embargo, es muy redundante, especialmente porque hemos decidido cuantificar bajo esta categoría los casos que utilizan las propias siglas del movimiento: MST.

Por lo que respecta al análisis cualitativo, desde los primeros años después de la fundación del MST, es decir, en el período 1984-1994 (primer período utilizado en este análisis), la revista Veja se apropia de un discurso que tiene como objetivo caracterizar el movimiento como violento y peligroso. En 1986, la revista recurre al término 'invasores' para definir a los miembros del MST que pretendían hacer la reforma agraria en el país. La palabra 'invasor' activa un sentido negativo, dado que en una sociedad capitalista livre, democrática e capitalista (recuperando aquí la visión de la sociedad de Veja) apropiarse de algo que no nos pertenece significa formar parte del lado violento de la sociedad y deslegitima cualquier acción hacia el cambio social. La denominación 'invasores' construye como referente la tierra poseída y refuerza y deslegitima al movimiento.

1. $[19 / 06 / 85$, p.20]

$\mathrm{Na}$ quinta-feira passada, os invasores distribuíram um documento em que dão um prazo de cinco dias ao governo para que lhes entregue a área invadida.

2. $[19 / 06 / 85$, p.20]

Da mesma forma que há os invasores de terra oportunistas, existem especuladores que jamais jogarão uma semente no terreno que compraram e até donos que na realidade possuem um papel e não uma gleba. 
La denominación assassinos en el ejemplo 3 atribuye al movimiento connotaciones claramente vinculadas con la violencia 'subjetiva' (Žižek, 2009), mediante la capacidad de cometer actos de gran atrocidad para lograr sus objetivos.

3. $[15 / 08 / 1990$, p. 35]

Degolado, o soldado cambaleou alguns passos, disparou um tiro a esmo e caiu no asfalto, onde os assassinos o deixaram agonizar até ser recolhido por um comerciante nas proximidades.

El ejemplo anterior forma parte de un reportaje en el que la revista adopta una estrategia discursiva notoriamente ofensiva, mediante la que busca impactar a sus lectores describiendo escenas de confrontación entre la policía e integrantes del MST. Dicha estrategia es también adoptada por Veja en los otros períodos contemplados en esta investigación. Así, entre los años 1995-1998, además de mantener denominaciones que deslegitiman el movimiento y lo tornan violento, la revista vincula la categoría 'violencia' con un matiz más ideológico y político al ligar el movimiento con prácticas

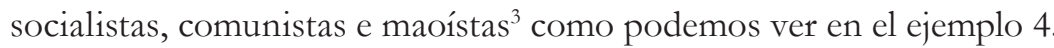

4. $[03 / 06 / 1998$, p. 46$]$

No campo ideológico, o MST é um liquidificador. Ali, existem os que se inspiram em Ernesto Che Guevara, simpatizantes do sandinismo nicaragüense, adeptos das táticas maoístas de começar a revolução pelo campo em direção às cidades, defensores de uma "pátria operária e socialista", tudo misturado com princípios da Teologia da Libertação, bênção das Comunidades Eclesiais de Base, de onde saiu boa parte de seus dirigentes, inclusive Stedile.

El tenor ideológico añadido a la categoría 'violencia' permanece en los períodos 1999-2002, 2003-2006 y 2007-2009 como recogemos en 5, 6, 7 y 8.

5. [27/06/01, p.110]

Os novos agricultores da bandeira vermelha vão entrar no empreendimento totalmente despreparados para lidar com o aparato que equipa a fazenda e sem dinheiro para fazê-lo funcionar.

6. [03/04/2002, p.46]

O MST ostenta em sua cúpula uma salada ideológica anacrônica que consegue compatiblizar maoistas, guevaristas, marxistas, fidelitas e até representantes de correntes políticas moderadas.

7. [08/09/2004, p.47]

Os professores utilizam, por exemplo, uma espécie de calendário alternativo que inclui a celebração chinesa, a morte de Che Guevara e o nascimento de Karl Marx. 
8. $[28 / 01 / 2009$, p.48]

Em seus capítulos não contemplados pelo Código Penal, o manual expõe uma organização claramente assentada sobre um tripé leninista com doutrinação política, centralismo duro e vida clandestina.

Además, en estos tres períodos políticos - especialmente a partir de 2002- la revista extrapola las fronteras ideológicas y recurre a denominaciones que buscan la criminalización del movimiento ante la opinión pública, como vemos en 9, 10, 11, 12 y 13.

9. $[18 / 06 / 2003$, p. 79]

O acampamento de Rainha, sua Canudos virtual, é povoado por miseráveis urbanos, mas também atrai aproveitadores de todos os tipos.

10. [26/04/2006, p. 41]

O escândalo não para por ai: os facínoras chefiados por João Pedro Stedile continuam a ser adubados com patrocínio estatal.

11. [26/04/2006, p. 42]

O MST também se beneficia de uma ingenuidade: o ideário politicamente correto que, espargido entre a classe média por professores universitários esquerdistas, camufla perante uma parte da opinião pública a sua verdadeira essência - a de organização criminosa- com a aparência de um movimento que defende a justiça social.

12. $[07 / 11 / 2007$, p. 126]

Esses bandos invadem fazendas e cobram resgate por seus proprietários.

13. [07/11/2007, p.127]

Os métodos desses marginais são tão violentos que assustam até as outras organizações de sem-terra que atuam na região.

Esta estrategia parece estar intrínsecamente ligada a los períodos políticos en los que la práctica discursiva de la revista se contextualiza, ya que en 2002 el país se encontraba en la campaña política presidencial en la que se eligió a Lula da Silva como presidente. En los siguientes años, con el PT en el poder, criminalizar al MST -que mantenía estrechas conexiones con el partido de Lula da Silva- fue la estrategia discursiva adoptada por Veja para cuestionar el PT y deslegitimar un movimiento que lo apoyó de manera significativa en las campañas presidenciales. En ese sentido, la revista se apropia de formas de discursos que objetivan la manipulación de la información y la deslegitimación del MST como agente de transformación social.

Por lo que respecta a la categoría 'grupo social', las denominaciones que utiliza Veja para referirse al movimiento difieren en los distintos períodos, especialmente en lo que se refiere a la diversidad léxica. En el período 1984-1994, por ejemplo, diferentes instancias sociales fueron convocadas a participar en movimientos progresistas a 
favor de cambios profundos en la sociedad post-dictatorial. Sirvan como ejemplo los siguientes extractos:

14. $[19 / 06 / 1985$, p.20]

Em Santa Catarina, existe um grupo de lavradores que se denomina Movimento dos Sem Terra e essa organização reivindica a imediata desapropriação de 1.000 hectares que seus membros ocupam no oeste do Estado.

15. [19/06/1985, p. 24]

Com disposição dos fazendeiros de levantar barricadas e a dos agricultores pobres de rompê-las, a ameaça de uma conflagração no campo ganha contornos cada vez mais nítidos.

16. [21/09/1994, p. 67]

Aí o cardápio melhora e um charque de segunda pode aromatizar o ambiente. É o spa dos miseráveis.

Lavradores, agricultores pobres y miseráveis representan al MST como un grupo social sin privilegios. En ese período, Veja acompaña el momento histórico e incluye a los sem-terra entre los movimiento sociales que pretenden cambios en la sociedad, en este caso en el sector agrario. Con todo, es significativo que durante esos años, la diversidad léxica es significativamente menor a la que encontramos entre 1995-1998, cuyo aumento debe ser explicado como una estrategia que reproduce la ideología del gobierno neoliberal de Cardoso, presidente de Brasil en aquel momento. En primer lugar, hay que resaltar que además de las denominaciones preferidas en el período 1984-1994 (tales como: lavradores, agricultores, famílias, posseiros ${ }^{4}$, entre otros), aparecen otras como las ejemplificadas a continuación:

17. $[23 / 04 / 1997$, p. 26]

Afinal, são gente honesta, que quer trabalhar a terra, educar seus filhos.

18. $[23 / 04 / 1997$, p. 26]

O que fazer com eles, os sem-terra, os pobres, os sem-nada.

19. [25/06/1997, p.32]

Dado que, entre os assentados, é expressivo o número de analfabetos, pode-se ter uma idéia de quanto é difícil elaborar um projeto ou usar novas tecnologias.

20. [03/06/1998, p.42]

Entre seus 100.000 seguidores, há de tudo: desempregados, analfabetos, agricultores arruinados, comerciários sem eira nem beira, gente que foi bóia-fria ou veio de favelas nas grandes cidades.

21. [03/06/1998, p.42]

Pois não é que uma bandeira tão arcaica, uma massa de pés descalços e uma estrutura tão antiquada agitam o Brasil de norte a sul? 
En el primer período del gobierno de Cardoso, el MST intensificó las ocupaciones de tierras para garantizar su derecho a la reforma agraria. Esto llevó a numerosos enfrentamientos con la policía. El más violento causó la muerte de 19 miembros del MST en el estado de Pará en 1996 (que se conoció como O Massacre de Eldorado dos Carajás). Este acto de violencia sacudió a la opinión pública y victimizó al movimiento, incluyendo la red de televisión más grande de Brasil -Globo-, que produjo una telenovela titulada $O \mathrm{R} e i$ do gando para hablar sobre el tema de la tierra en el país. Se observa que en este período $V_{e j a}$ diversifica su repertorio lingüístico y opta por denominaciones que identifican al MST en la categoría 'grupo social' (a diferencia de lo que ocurre en el período siguiente, 1999-2002). Es interesante notar que las prácticas discursivas de Veja, y de gran parte de los medios de comunicación brasileños, no siguen un flujo continuo sino que responden a estrategias determinadas por los distintos períodos históricos. Aunque esto no exime a la revista para representar los intereses oligárquicos que buscan desmantelar cualquier intento de cambiar la sociedad, Veja mitiga o suaviza su discurso de acuerdo a su agenda en cada momento político determinado. Además, en los períodos de 1995-1998 (en especial en 1997, cuando el MST intensifica su lucha a favor de la reforma agraria) y de 1999-2000, la designación assentado(s) es utilizada por la revista para referirse al movimiento. El verbo assentar indica una posición-sujeto del gobierno que actúa bajo la ley y promueve la reforma agraria pacífica y lentamente. Al referirse al MST como assentados, la estrategia discursiva de Veja tiene como objetivo mostrar a la opinión pública que el gobierno de Cardoso está comprometido con la reforma agraria y que cualquier acto de rebelión del MST expone su ilegitimidad social y política.

22. [05/06/1997, p.32]

O Censo também comprova uma suspeita antiga, que os assentados tem baixa produtividade aquém da média nacional...

23. [25/06/1997, p. 33]

O número de assentados dobrou nos dois últimos anos, pulando de 100000 para 200000 .

24. [05/05/1999, p. 50]

Depois de semear e colher, os assentados precisam de acesso a crédito e uma taxa de juros muito baixa para que possam honrar as prestações.

En los extractos anteriores también se perciben dos posiciones de Veja. Una primera relacionada con el gobierno de Cardoso, que duplicó el número de familias asentadas durante su mandato y, una segunda cuestionando si la reforma agraria es algo realmente factible dada la gran inversión por parte del gobierno y la 'falta de preparación' de los sin tierra.

En el período 2003-2006, también se nota un aumento en la diversidad léxica usada por la revista al incluir al MST en la categoría 'grupo social'. 
25. [18/06/2003, p.80]

Os que ficam são os mais miseráveis, atraídos pelas cestas básicas enviadas pelo governo.

26. [18/06/2003, p.74]

O acampamento está sendo montado ao longo de uma estrada, um barraco ao lado do outro, numa longa fila. A maior parte dos "acampados" vive em áreas muito pobres de Presidente Epitácio e lugarejos vizinhos. São biscateiros, desempregados, motoristas, pequenos vendedores e também lavradores, pessoas que desenvolvem atividades econômicas marginais, desvinculadas da grande produção.

27. [08/12/2004, p.54]

Segundo cálculo feito pelo professor Francisco Graziano, ex-presidente do Incra e uma das maiores autoridades no assunto, das 120.000 famílias acampadas apenas a metade vive sob lonas e barracos de madeira.

Como se observa en los anteriores extractos, en la primera fase del gobierno de Lula da Silva, Veja reformula su repertorio lingüístico e incluye designaciones como miseráveis, acampados (famílias acampadas), biscateiros, desempregados, etc. en una tentativa de deslegitimar no solo al MST sino también al gobierno de Lula da Silva que, según la revista, no cumple con sus propuestas electorales en lo que respecta a la reforma agraria. Además, los términos miseráveis, biscateiros, desempregados, motoristas, y pequenos vendedores favorecen una interpretación de que el MST dejó de ser un movimiento típicamente agrario y pasa a incorporar a otro grupo de ciudadanos totalmente desvinculado de la cuestión agraria. Así, Veja trata de mostrar que las reivindicaciones del movimiento y, por lo tanto, la reforma en el sector agrario, son difícil de conseguir dada la diversidad de las personas (muchas de ellas poco cualificadas para trabajar la tierra) que participan en el movimiento.

En el período 2007-2009, la designación assentado vuelve a aparecer tímidamente en el repertorio lingüístico de la revista, dados los avances conseguidos en el sector agrario brasileño durante el gobierno del PT.

28. [03/10/2007, p. 72]

Os assentados reivindicam aprender o idioma a pretexto de melhorar a comunicação com os "companheiros” dos países da America Latina.

29. [03/10/2007, p. 72]

Já são dezesseis universidades públicas que oferecem graduação exclusiva aos assentados.

En cuanto a la categoría 'actor político', observamos que en el período 1984-1994 (más hacia el último año de ese período), Veja solo utiliza una denominación para referirse al MST. Se trata de 'militante', palabra llena de sentido político utilizada para referirse a los sin tierra: 
30. [21/09/1994, p.68]

Espalhado pelo Brasil, o MST reúne cerca de 700 militantes liderando 19000 sem-terra acampados. Essa teia, que cobre o mapa do Brasil e desperta suspeitas em muitos donos de terras, recebe ajuda de várias fontes.

Esta estrategia de la revista de apenas incluir a los sem-terra dentro de una categoría política puede ser explicada contextualizando el momento político de este período. El MST fue fundado en 1984, pero comenzó a ganar fuerza en los años 90, cuando el movimiento se sumó al amplio número de movimientos sociales progresistas que surgen en Brasil al finalizar la dictadura. Sin embargo, esto comienza a cambiar en los últimos años del período 1995-1998, cuando el movimiento adquiere un tono más político en sus demandas en las agendas de la reforma agraria y se consolida como una fuerza de oposición del gobierno de Cardoso. Con la intensificación de las ocupaciones de tierras, Veja comienza a adoptar una práctica discursiva diferente y pasa a considerar el movimiento como una fuerza de oposición al gobierno. Además, la revista comienza a usar las siglas MST para referirse al 'actor político'.

31. [28/08/1996, p.69]

Eles pertencem a uma organização vitoriosa que em onze anos de existência instalou 139.000 famílias em 7,2 milhões de hectares - uma àrea equivalente à dos Estados do Rio de Janeiro e Sergipe juntos.

32. [03/06/1998, p.47]

Da porteira à portaria - Com catorze anos de idade, o MST transformou-se na única força de oposição capaz de chacoalhar o governo.

Es interesante resaltar que al referirse al MST como una organização vitoriosa, la revista invisibiliza a las 139.000 famílias del movimiento. Es decir, para Veja, no fue a través de la lucha y de la reivindicación de esas familias por lo que se consiguió que 7,2 millones de hectáreas de tierra fueran puestas a disposición de la reforma agraria, sino más bien eso se representó como el éxito de la lucha de una organización política llamada MST.

En los tres períodos siguientes a 1995-1998, esta estrategia se impone y se intensifica a medida de la revista opta indistintamente por denominaciones como sem-terra y MST para referirse a una organización política. Por lo tanto, hay una disminución en la diversidad con respecto a las denominaciones lingüísticas utilizadas por Veja para referirse al movimiento. La designación sem-terra se une a MST, y adquiere un tono distinto en el discurso de la revista. Sem-terra adquiere un sentido político con la creación de un nuevo sujeto discursivo en el contexto político en Brasil, a diferencia de cómo se usó esa denominación en el período 1984-1994. 


\section{CONCLUSIONES}

Los medios de comunicación brasileños, por lo general representados por las poderosas oligarquías, se apoderan de un discurso ideológico para (des)legitimar todo pensamiento determinado a cuestionar el modelo neoliberal y por lo tanto, el status quo. En el caso específico del MST, esta práctica de los medios de comunicación es validada a través de las representaciones adoptadas por el semanario Veja para representar el movimiento.

Nuestros resultados sugieren que la revista Veja, en los cinco períodos analizados, siempre utilizó estrategias discursivas y opciones léxicas negativas con el fin de desactivar cualquier iniciativa del MST para promover la reforma agraria y la justicia social en el país. Sin embargo, el uso de estas estrategias se intensifica o suaviza de acuerdo con la agenda de la revista en cada momento político en Brasil. Durante los períodos relacionados con la campaña pre-electoral del presidente Lula da Silva y durante sus dos mandatos hubo un aumento significativo de la diversidad lingüística medida a partir de las elecciones lexicales referentes a la categoría 'violencia'.

Además, durante el período 1995-1998, especialmente en 1996, Veja utiliza las opciones léxicas más suavizadas y vincula a los participantes del MST en la categoría 'grupo social' dada la gran repercusión que tuvo la Masacre de Eldorado dos Carajas en el país.

El léxico adoptado por Veja para referirse al MST como 'grupo social' también cambia según los momentos políticos de Brasil (1984-1994 período: 1 denominación - militantes. Esto cambia a finales de 1995-1999, cuando el MST adquiere una postura contraria al gobierno de Cardoso y se intensificó aún más durante el gobierno de Lula da Silva cuando Veja visualiza el movimiento como una fuerza política en el país.

Desde su fundación, el discurso de la revista Veja ha sido construido para representar a las élites brasileñas en su búsqueda constante para preservar el status quo en la sociedad. Por lo tanto, la construcción de des(legitimidad) del MST está intrínsecamente ligada al control discursivo de los grupos en el poder. Los momentos políticos, sin embargo, contribuyen de manera significativa al hecho de que la revista utilice un discurso más híbrido en relación con el movimiento u opte por homogeneizarlo, en busca de un desmantelamiento de las prácticas transformadoras e igualitarias del MST.

El presente trabajo forma parte de una investigación más amplia sobre la representación contemporánea de los movimientos sociales en la prensa latinoamericana. En consecuencia, asumimos las limitaciones del mismo y lo entendemos como una primera aproximación que necesita completarse con análisis discursivos más completos, que tengan en cuenta otras dimensiones del análisis lingüístico. 


\section{REFERENCIAS BIBLIOGRÁFICAS}

Almeida Brasil, M. R. (2008). Mídia massiva e MST no discurso ecológico da contemporaneidade. Ponencia presentada en el XXXI Congreso Brasilero de Ciencias de la Comunicación, Rio Grande do Norte, Natal, Brasil.

Althusser, L. (1970). Idéologie et appareils idéologiques d'État (Notes pour une recherche). La Pensée, 151, 3-38.

Azevedo, M. T. (2005). Veja o MST! -Um frame revelado. Revista Brasileira de Lingüística Aplicada, 152(5), 141-153.

Azevedo, K. F. (2008). (Des)legitimação: Ações discursivo-cognitivas para o processo de categorização social. Tesis doctoral, Universidad Federal de Pernambuco, Brasil.

Ayoub, A. H. (2007). Mídia e Movimentos Sociais: A Satanização do MST na Folha de São Paulo. Estudos em Jornalismo e Mídia, 4(1), 79-93.

Bell, A. \& Garrett, P. (Eds.) (1998). Approaches to Media Discourse. Oxford: Blackwell.

Benetti, M. (2007). A ironia como estratégia discursiva da Revista Veja. Ponencia presentada en el XVI Encontro da Campós na UTP em Curitiba, Paraná, Brasil.

Bernardo Paniagua, J. Ma , López García, G., Sancho Cremades, P. \& Serra Alegre, E. (Eds.) (2007). Critical discourse analysis of media texts. Valencia: Universidad de Valencia.

Blommaert, J. (2005). Discourse. Cambridge: Cambridge University Press.

Fairclough, N. (1989). Language and power. Harlow: Longman.

Fairclough, N. (1995). Media discourse. Londres: Arnold.

Fairclough, N. (2003). Analysing discourse: Textual analysis for social research. Londres: Routledge.

Fairclough, N. \& Wodak, R. (1997). Critical discourse analysis. En T. A. van Dijk (Comp.), Discourse as social interaction (pp. 258-284). Londres: Sage.

Fernández Parrat, S. (1998). El reportaje en prensa: Un género periodístico con futuro. Revista latina de comunicación social, 4 [en línea]. Disponible en: http://www.ull.es/publicaciones/latina/z8/r4absonia.htm

Ferreira Giovando, M. \& Sombra, E. (2008). A construção de sentido pela proposta metodológica da análise crítica do discurso: O MST nas páginas de Veja (2003-2004). Revista, 3(5), 1-10.

Fowler, R. (1991). Language in the news: Discourse and ideology in the press. Londres: Routledge.

Franco, L. M. (2003). O MST na Folha de São. Paulo e no Jornal dos Trabalhadores Rurais Sem Terra: Análise das Práticas Discursivas. Tesis doctoral, Universidad de São Paulo, São Paulo, Brasil.

Galasiński, D. \& Skowronek, K. (2001). Naming the nation. A critical analysis of names in Polish political discourse. Political Communication, 18(1), 51-66.

Gonçalves, E. M. (2004). O MST e a midia: Conflito no campo e na linguagem. Ponencia presentada en el Encontro anual da associação nacional de programas de pósgraduação em comunicação social, UMESP, São Paulo, Brasil. 
Guilherme, A. S. (2008). Revista Veja e o MST durante o governo Lula/PT. Revista Urutaguá, 15, 116-125.

Indursky, F. (1999). De ocupação a invasão: Feitos de sentido no discurso do/sobre o MST. En F. Indursky \& M.C. Leandro Ferreira (Org), Os múltiplos territórios da Análise do Discurso (pp. 173-188). Porto Alegre: Sagra-Luzzatto.

Indursky, F. (2002). O entrelaçamento entre o político, o jurídico e a ética no discurso do/sobre o MST: Uma questão de lugar-fronteira. Revista da ANPOLL, 12, 111-132.

Johnson, S. \& Ensslin, A. (2007). Language in the media: Representations, identities, ideologies. Londres: Continuum.

Johnson, S. \& Milani, T. M. (Eds.) (2010). Language ideologies and media discourse. Londres: Continuum.

KhosraviNik, M. (2010). The presentation of refugees, asylum seekers and immigrants in British newspapers. A critical discourse analysis. Journal of Language and Politics, 9(1), 1-28.

Martín Serrano, M. (1986). Teoría social de la comunicación. Madrid: Alianza.

Montgomery, M. (2011). Discourse and the news. En K. Hyland \& B. Paltridge (Eds.), The Continuum Companion to Discourse Analysis (pp. 213-227). Londres: Continuum.

Moura dos Santos, M. (2007). Sentidos e discursos dos jornais nordestinos sobre o MST. Estudos em Jornalismo e Midia, 4(1), 94-108.

Ondetti, G. A. (2008). Land, protest, and politics. The landless movement and the struggle for agrarian reform in Brazil. University Park, (PA): The Pennsylvania State University.

Passos, N. M. (2008). A revista Veja e a invenção do 'MST terrorista': Um estudo sobre a cultura da opressão no Brasil pós 11 de setembro. Tesis doctoral, Universidade Federal do Mato Grosso, Brasil.

Pereira, W. (2001). As mídias e as linguagens totalitárias. Biblioteca online de ciências da comunicação [en línea]. Disponible en: http://www.bocc.ubi.pt/pag/pereira-wellington-midiologia.pdf

Richardson, J. (2007). Analysing newspapers: An approach from critical discourse analysis. Londres: Palgrave Macmillan.

Rodríguez, F. \& Williams, J. (2011). Representación socio-discursiva de los actores implicados en el ataque a una joven ecuatoriana en un tren de cercanías de Barcelona: Estudios de caso. Revista Signos. Estudios de Lingüistica, 44(77), 275-294.

Souza, E. F. (2004). Do silêncio à sataniz̧ação: O discurso de Veja e o MST. São Paulo: Annablume.

Tfouni, L. V. \& Romão, L. M. (2004). O MST no discurso jornalístico: Confronto de posições e formações discursivas. Cadernos de Estudos Linguísticos, 46(2), 253 267.

van Dijk, T. A. (1986). Racism in the press. Londres: Arnold.

van Dijk, T. A. (1997). Ideology. A multidisciplinary approach. Londres: Sage. 
van Dijk, T. A. (2000). El discurso como interacción en la sociedad. En T. A. van Dijk (Comp.), El discurso como interacción social (pp. 19-66). Barcelona: Gedisa.

van Leeuwen, T. (1996). The representation of social actors. En C. R. Caldas Coulthard \& M. Coulthar (Eds.), Texts and Practices (pp. 32-70). Londres \& Nueva York: Routledge.

Vieira, F. A. \& Giuliani, G. M. (2007). Navegando contra a maré: A relação entre o MST e a mídia. Tesis doctoral, Universidade Federal do Rio de Janeiro, Rio de Janeiro, Brasil.

Wodak, R. (2001). The discourse-historical approach. En R. Wodak \& M. Meyer (Eds.), Methods of Critical Discourse Analysis (pp. 63-94). Londres: Sage.

Wodak, R. (2011). Critical discourse analysis. En K. Hyland \& B. Paltridge (Eds.), The Continuum Companion to Discourse Analysis (pp. 38-53.). Londres: Continuum.

Žižek, S. (2009). Sobre la violencia. Seis reflexiones marginales. Barcelona: Paidós.

\section{NOTAS}

1. Junto a los artículos de opinión, en el período analizado, Veja publicó también numerosos artículos y editoriales relacionados con la cuestión agraria (Ondetti, 2008), que no han sido objeto de nuestro análisis.

2. Datos extraídos de http://publicidade.abril.com.br/marcas/veja/revista/informacoes-gerais

3. Dado que la revista defiende los intereses de las grandes oligarquías y lucha por mantener el status quo, parece razonable establecer que cualquier conexión del MST con prácticas que cuestionen y busquen cambios profundos en la sociedad serán consideradas violentas por Veja.

4. El término 'posseiro' es utilizado por Veja para definir a un grupo de trabajadores rurales que reivindica cambios en el sector agrario de Brasil y, por tanto, pertenece al eje discursivo 'grupo social' (con excepción de 'posseiros armados e desarmados' que se optó por interpretarlo en la categoría 'violencia' dado los adjetivos que lo modifican). 